\title{
1 The golf ball method for rapid assessment of grassland structure
}

2 Nick Schultz ${ }^{1}$, Marie Keatley ${ }^{2}$, Mark Antos ${ }^{2}$, Nathan Wong ${ }^{3}$, Claire Moxham ${ }^{4}$, Brad Farmilo ${ }^{4}$,

3 John W. Morgan ${ }^{5}$

$4{ }^{1}$ School of Applied and Biomedical Science, Federation University Australia, PO Box 663,

$5 \quad$ Ballarat VIC 3353, Tel: +61 4 06855227, email: n.schultz@ federation.edu.au

$6 \quad{ }^{2}$ Parks Victoria, Level 10, 535 Bourke Street, Melbourne, VIC 3000, Australia

$7{ }^{3}$ Trust for Nature Victoria, Level 5/379 Collins Street, Melbourne, VIC 3000 Australia

$8{ }^{4}$ Arthur Rylah Institute for Environmental Research, Department of Environment, Land, Water

9 and Planning, 123 Brown St, Heidelberg, VIC 3084, Australia

$10{ }^{5}$ Department of Ecology, Environment and Evolution, La Trobe University, Bundoora VIC 3086,

11 Australia

Acknowledgements

13 Numerous agencies have provided support and funding for the development of the golf ball method: Parks Victoria, North Central Catchment Management Authority, the Australian Government, Trust for Nature, Department of Environment, Land, Water and Planning (DELWP), and the Glenelg-Hopkins Catchment Management Authority through funding from the Australian Government's National Landcare Programme via the Sustainable Environment, Threatened Species and Communities (SETSC) VVP Grassland Monitoring program.

\section{Byline}

Nick Schultz is a research fellow at the School of Applied and Biomedical Science, Federation

University Australia (PO Box 663, Ballarat VIC 3353, Tel: +61 4 06855227, email: n.schultz@federation.edu.au). Marie Keatley and Mark Antos are senior scientists at Parks Victoria (Level 10, 535 Bourke Street, Melbourne, VIC 3000, Australia). Nathan Wong is a conservation planning advisor with Trust for Nature (Level 5/379 Collins Street, Melbourne, VIC 3000 Australia). Claire Moxham and Brad Farmilo are ecologists at the Arthur Rylah Institute for Environmental Research (Department of Environment, Land, Water and Planning, 123 Brown St, Heidelberg, VIC 3084, Australia). John Morgan is part of the Department of Ecology, Environment and Evolution, La Trobe University (Bundoora VIC 3086, Australia). This project arose from our mutual interest in monitoring and managing grassy ecosystems for biodiversity conservation.

This is the author manuscript accepted for publication and has undergone full peer review but has not been through the copyediting, typesetting, pagination and proofreading process, which may lead to differences between this version and the Version of Record. Please cite this article as doi: 10.1111/emr.12254

This article is protected by copyright. All rights reserved 
Received Date : 23-Sep-2016

Revised Date : 10-Feb-2017

7 Accepted Date : 23-Feb-2017

Article type : Research report

The golf ball method for rapid assessment of grassland structure

\section{Summary}

A key task for native grassland managers is to assess when biomass reduction is necessary to maintain plant and animal diversity. This requires managers to monitor grassland structure. Parks Victoria and La Trobe University developed a method for rapid assessment of grassland structure using golf balls. Baker-Gabb et al. (2016) provide an example of where the method has been used to manage grassland structure to fayour an endangered bird, the Plains-wanderer (Pedionomus torquatus). In this paper, we provide further critical analysis of the method using three datasets collected across different parts of Victoria that relate golf ball scores to various habitat attributes. We demonstrate how the golf ball score provides a good surrogate for key aspects of grassland structure. We show that the method does not provide a reliable surrogate for aboveground biomass or vegetation cover, though we discuss how biomass and cover are not particularly good indicators of grassland structure. We argue that elements of grassland structure may be better correlated with desired conservation outcomes (e.g. plant species diversity, or the presence of a particular species) than biomass or cover alone. We discuss examples of how the golf ball method has been used, and how it can be improved. The method will be particularly useful where a link can be demonstrated between golf ball scores and desired conservation outcomes, such as in the case of the Plains-wanderer.

Keywords: Grassland, monitoring and evaluation, conservation management, disturbance, faunal habitat 
31 A major challenge for native grassland management in south-eastern Australia relates to the necessity 32 to manage disturbance regimes (by burning, grazing or slashing) that reduce biomass to alter vegetation structure. Without disturbance to the vegetation, biomass may accumulate and smother intertussock flora, preventing seedling recruitment and reducing plant species diversity (Morgan 1998). In extreme cases, biomass accumulation smothers dominant tussock grasses, leading to their decline and replacement with annual exotic species (Morgan \& Lunt 1999). Fauna, too, may prefer particular grassland structures. For example, the grassland bird Plains-wanderer (Pedionomus torquatus) is sensitive to grassland structure, which can either be too dense or too open (Baker-Gabb et al. 2016). Striped legless lizard (Delma impar) is thought to be suited to complex grassland structure (Howland et al. 2016), and populations may decline with an increase in the proportion of short grass and bare ground (Dorrough \& Ash 1999). In addition, Howland et al. (2014) showed that in Australian grasslands and grassy woodlands, reptile abundance, species richness and species diversity is highest with low grazing intensity, suggesting these measures respond positively to grass cover.

The rate that biomass accumulates varies with grassland productivity in south-eastern Australia, and hence so too does the required frequency of disturbance (Schultz et al. 2011). Productive grasslands in wetter regions-such as Themeda grasslands in the Victorian Volcanic Plains (VVP)—quickly accumulate dead grass (Morgan \& Lunt 1999), which decomposes very slowly, and may require frequent disturbance (around once every three years; Lunt \& Morgan 1999) to negate the threat of smothering. By contrast, dead grass in less productive and drier grasslands-such as those dominated by Austrostipa spp. and Rytidosperma spp. in the Victorian Riverina-does not appear to accumulate over long periods (Schultz et al. 2011), but instead may decay (or blow away) relatively quickly, negating the need for frequent disturbance. Figure 1 shows the main areas of plains grassland in Victoria, including the VVP and Victorian Riverina.

For grassland managers, disturbance interventions might be used to negate high grass cover, grass height and litter levels that can compromise native plant and animal diversity (Morgan 2015). However, choosing appropriate disturbance regimes for native grasslands is difficult as biomass accumulation varies not only among grasslands in different geographic regions, but also within grasslands due to climate variability (White et al. 2014). To date, grassland ecologists have generally focussed on biomass accumulation as a driver of grassland dynamics, and indeed it is the accumulation of biomass over time that changes grassland structure. However, biomass itself (generally measured as g. $\mathrm{m}^{-2}$ or tonnes.ha ${ }^{-1}$ ) can be a poor indicator of structure (Morgan 2015), and might not be particularly useful to grassland managers. For instance, Figure 2 depicts two hypothetical grasslands with equal biomass, but very different structure. Other aspects of grassland 
structure - such as how open a grassland is, or how much light is available for establishing plantsare more likely to be directly related to conservation outcomes, such as maintaining plant species diversity or providing habitat for fauna.

To meet the challenges of grassland management, a method for the assessment of grassland structure is necessary. Techniques for measuring grassland structure vary from being rapid and coarse (e.g. plant cover estimates by eye), to time-consuming and detailed (e.g. point quadrats); however, in order for a technique to be useful to grassland managers it needs to be quantitative, repeatable, rapid and simple (Gibbons et al. 2009). This should allow managers to confidently respond to changes in vegetation condition (e.g. in response to rainfall or management). Seddon et al. (2011) also acknowledge the challenge of achieving a balance between simple techniques and adequate discrimination of condition between sites.

In an attempt to provide a grassland assessment method that meets these challenges, the 'golf ball method' was developed by La Trobe University, in conjunction with Parks Victoria (Schultz 2007, Schultz \& Morgan 2010). It is based on the idea that golf balls lying in grassland vegetation will be obscured from a bird's-eye-view to varying degrees, depending on the amount and structure of vegetation. Hence, the visibility of golf balls can be used to evaluate the current structure (or 'state') of a grassland. Box 1 provides a description of the method. The method has gained wide use by grassland managers in Victoria, in part due to its promotion by Parks Victoria and Trust for Nature. Here, we examine the robustness of the scoring method and the relationship of golf ball scores to various measures of grassland structure and plant diversity. We also discuss current applications of the method, and how it can be improved.

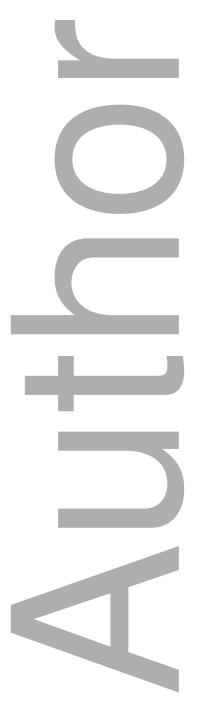




\section{Box 1. Instructions provided to users of the golf ball method}

Instructions are provided at www.bit.ly/GrassMonitoring, or email the authors for a copy. These ask the operator to place a $1-\mathrm{m}^{2}$ frame in grassland vegetation. This should be done at randomised locations, as specified by the project's monitoring design. Eighteen golf balls are then dropped, one at a time, into the vegetation within the frame, at different points around the $1 \mathrm{~m}^{2}$ area. The balls should fall through the vegetation to ground level. If the balls rest on top of grass tussocks, some gentle shaking of tussocks may be required to allow the balls to fall to ground level. Disturbance within the frame should be kept to a minimum. A digital camera should be held above the frame (around $160-170 \mathrm{~cm}$ ) to capture the entire frame in a bird's-eye-view photo, which will be used to assign a visibility score. Scoring can also be done in the field without a camera. Photos are scored as such: a ball is scored as 1 if more than $90 \%$ of the ball is visible; a ball is scored as 0 if less than $33 \%$ is visible. All other balls are scored as 0.5 . Hence, a low total score in a frame suggests a closed grassland structure, and high vegetation cover, whereas an open structure and low vegetation cover will give a high golf ball score. In some grasslands with high vegetation cover, golf balls may rest on top of dense tussocks or saltbushes and will not fall through to ground level with gentle shaking. In these situations, if the average height of the vegetation is $\geq 8 \mathrm{~cm}$, these balls should be scored as zero. Figure 3 shows a scored photograph. Further details about conducting the method, including advice for monitoring design, and establishing conservation targets and management objectives, are provided in Parks Victoria (2014) and Antos (2016).

\section{Applications of the method}

88 Three studies in Victorian grassy ecosystems demonstrate the application of the golf ball method to 89 conservation management. Baker-Gabb et al. (2016) used the golf ball method to monitor Plains90 wanderer habitat and population size. The authors assert that grassland vegetation should be maintained in the 13.5-17.5 golf ball score range to maintain suitable Plains-wanderer habitat. Golf ball scores are now used to help guide management decisions to implement or remove disturbance regimes (grazing and fire) to grasslands being managed for Plains-wanderer conservation.

Brown and Scroggie (2012) used the golf ball method to help discern the preferred habitat of the threatened Hooded Scaly-foot (Pygopus schraderi, a legless lizard) in the Victoria Riverina grasslands. They found no significant difference in golf ball score between Hooded Scaly-foot sites 
and random sites in similar vegetation, and showed that the cover of cryptogams and the incidence of spider holes and soil cracks were greater determinants of Hooded Scaly-foot habitat. In this way, the golf ball scores helped to rule out grassland structure as a determinant of Hooded Scaly-foot habitat.

Golf ball scores were also used in an attempt to determine structural preferences of Golden Sun Moth (Synemon plana) at Derrimut Grassland Reserve in the VVP (Griffith \& Nano 2011). This was important work, as previous research on the Golden Sun Moth has focussed on the species of tussock grasses preferred by the moth (Braby \& Dunford 2006, Richter et al. 2013), but not grassland structure. Although the study suggested that Golden Sun Moth prefer slashed paddocks with an open grassland structure, the golf ball score was not able to discern structural differences between slashed and unslashed paddocks. This may be due to uniformly-low grassland biomass at the time of monitoring (2008, a dry period). Hence, moth habitat preferences might be more evident during periods of greater biomass production, when there is greater differentiation between sites with high biomass and those for which biomass is experimentally reduced.

\section{Repeatability of assigning golf ball scores}

Any rapid assessment technique must be repeatable and reliable if it is to be widely adopted. To determine how much observer variation occurs when assigning golf ball scores, we used 21 independent observers, including 13 post-graduate students from the Department of Botany, La Trobe University, and eight staff members at Parks Victoria. The observers had no prior knowledge of the method but were trained in biological observation. Each observer was introduced to the method of scoring golf balls and an example dataset was scored as a demonstration. Observers were then asked to independently score 12 standard photographs provided by Parks Victoria. The photographs spanned a range of golf ball scores (0.5-18), and responses were compared to a 'benchmark' score agreed upon by two experts (J. Morgan and M. Keatley).

There was some variation in the scoring of golf ball visibility by independent observers (Figure 4), and observers tended to underestimate the golf ball scores compared to the benchmark scores. Relative to the benchmark scores, observers correctly identified high scores (>16) and low scores $(<3)$, but identified intermediate scores with less accuracy and consistency. Importantly, all observers correctly identified the differences between grasslands with an open structure (high ball scores: 1518 ) and those with a closed structure (low ball score: 0-5). Small departures in golf ball score of the observers from the benchmark are unlikely to negate the ability of the method to be indicative of grassland structure. Furthermore, this was the first attempt by the observers at scoring photos, and they may become more consistent with greater experience. Overall, we believe the data show that the method has performed quite well in the trial, and suggest that estimation of grassland structure using the method is fairly robust against observer variation. 


\section{Relationship of golf ball scores to grassland attributes}

133 The golf ball scores are an integrative measure of things we (as grassland ecologists and managers) intuitively understand, such as the structure, density and patchiness of the grassland. Nevertheless, we need to analyse the relationship of golf ball scores to grassland attributes to help understand what we are measuring. To achieve this we analysed three datasets based on extensive monitoring of golf ball scores and associated vegetation attributes: (1) the La Trobe University (LTU) dataset, collected in 2010 and spanning the range of grasslands and grassy woodlands occurring across Victoria; (2) the Parks Victoria (PV) dataset, collected between 2009 and 2015 in the plains grasslands of the Victorian Riverina (typically drier and less productive grasslands); and (3) the Arthur Rylah Institute (ARI) dataset, collected in 2015 in the grasslands of the VVP (typically wetter and more productive grasslands). The ARI dataset incorporated sites from both private paddocks (largely maintained by grazing) and public roadsides (largely maintained by fire). Figure 1 shows the location of sites at which data was collected for each dataset. The supporting information provides details of the data collection for each dataset.

\section{LTU datase}

The LTU data includes measures of golf ball scores, vegetation cover, biomass and species richness.

148 The correlation between golf ball score and vegetation cover was highly significant $\left(\mathrm{p}<0.001, \mathrm{R}^{2}=\right.$ 149 0.453; Figure 5a). Likewise, the correlation of golf ball scores to biomass was highly significant ( $\mathrm{p}$ 1500.001 ) but weaker $\left(R^{2}=0.308\right)$, particularly when the golf ball score is less than 10 (Figure $5 \mathrm{~b}$ ). This weak correlation is expected; as demonstrated in the hypothetical grassland structures in Figure 2, grasslands with very different structures may have similar biomass, negating any potential relationship between biomass and the golf ball scores, particularly when data is collected from a range of grassy vegetation types across a broad biogeographical range.

There was no correlation between golf ball scores and total species richness (Figure 5c). Despite the conventional wisdom that an open grassland structure allows greater coexistence of species, this is also not surprising, particularly given the range of different sites sampled. Grasslands and grassy woodlands exist in a wide range of condition states, and differences in management history create a large degree of variability in species richness which may override the impact of current grassland state. For example, we assume that a relatively open grassland state is required to maintain plant species diversity - however, a grassland might be open due to factors that do not favour species diversity (e.g. heavy sheep grazing, recent cultivation). As such, the golf ball scores are more likely to be correlated with species richness (1) over time at a single site, or (2) among sites in similar ecological condition or with similar ecological histories. This needs to be tested.

\section{PV dataset}


The PV dataset measured the cover and height of different vegetation components, such as native and exotic grasses, native and exotic forbs, bare ground, litter and cryptogams. We present four correlations of golf ball scores with vegetation attributes (Figure 6), all of which are highly significant $(\mathrm{P}<0.001)$. The correlations of golf ball scores with vegetation cover and bare ground, whilst significant, do not explain a high proportion of variability in the data $\left(\mathrm{R}^{2}=0.44\right.$ and 0.28 , respectively; Figure 6a and 6b), and show only that there are no low golf ball scores at high bare ground or low vegetation cover-all other combinations of golf ball scores with bare ground or vegetation cover are possible. For example, plots with vegetation cover of $80-100 \%$ can demonstrate the full range of golf ball scores (0-18; see Figure 6a). We interpret this data to support our claim that vegetation cover (and bare ground) can be poor predictors of grassland structure or openness. For instance, the space between tall perennial grass tussocks in an 'open' grassland structure could be bare ground, or it could be a low (say, $<3 \mathrm{~cm}$ ) cover of forbs or grasses.

There are other vegetation attributes, however, that are better correlated with golf ball scores than vegetation cover and bare ground. The attribute 'grass cover $\times$ grass height' (Figure 6c) represents an approximation of the volume of grass in a $1-\mathrm{m}^{2}$ plot, and explains a higher proportion of the variability in the data $\left(R^{2}=0.70\right)$. This relationship shows that golf ball scores generally increase (become more open) with decreasing grass volume. Figure $6 \mathrm{~d}$ shows the cover of all grassland components (bare ground, litter, crytogam and vegetation cover) that are less than $12 \mathrm{~cm}$ in height, and this also explains a higher proportion of variability in the data $\left(\mathrm{R}^{2}=0.72\right)$. This relationship provides an estimation of the space available between large perennial tussocks, and golf ball scores generally increase as this measure increases. These correlations support the idea that golf ball scores provide a measure of grassland openness, and may be more informative about grassland structure than measures such as vegetation cover or biomass.

190 Correlations between golf ball scores and grassland attributes demonstrated a variety of responses, 191 with none of the correlations explaining as much variation as the LTU and PV datasets. Vegetation cover had a negative and highly significant relationship with golf ball score in sites managed with fire

193 (i.e. public grasslands; Figure 7a), but was not significant in sites managed by grazing (i.e. private grasslands; Figure 7b). A significant negative relationship between golf ball scores and 'grass cover $x$ grass height' was also observed (Figure 7d); however the correlation explained substantially less variation than the PV dataset $\left(\mathrm{PV} \mathrm{R}^{2}=0.719 \mathrm{cf}\right.$. ARI $\left.\mathrm{R}^{2}=0.221\right)$. Unlike the PV dataset, there was no significant relationship between golf ball score and bare ground cover (Figure 7c). We propose that the differences observed may be related to the higher productivity of the VVP (compared to the Victorian Riverina), and suspect a different relationship between grassland structure and bare ground exists in the VVP. In lower productivity grasslands, like those investigated in the PV dataset, inter- 
201

202

203

204

205

206

207

208

209

210

211

212

213

214

215

216

217

218

219

220

221

222

223

224

225

226

227

228

229

230

231

232

233

234

235

tussock spaces are likely to be comprised of bare ground and cryptogamic crust, whereas in VVP grasslands, bareground is less likely. In addition, grazing is likely to exacerbate this trend by promoting lateral growth (Noy-Meir 1993, Andreasen et al. 2002), leading to grassland structure that resembles a lawn, and creating a situation in which both golf ball scores and vegetation cover can be high. The PV data set demonstrated the potentially poor correlation between vegetation cover and golf ball scores, though we believe the higher productivity in the VVP further diminishes this relationship. The correlation between vegetation cover and golf ball scores was poorer on private land (which is predominantley managed by grazing) than on public land (which is predominantly managed by fire). This supports the idea that grazing promotes lawn-type growth, which would further diminish the correleation between golf ball scores and vegetation cover. As such, we see the purpose of using the golf ball method in the VVP as to provide a useful measure of grassland openness, not biomass or cover. There may be more useful vegetation components to measure in conjunction with golf ball scores to help test for the openness of grassland vegetation. For example, a separate estimate of the cover of low vegetation $(<3 \mathrm{~cm})$ might help to discern lawn-like vegetation from tussock grass cover that has larger influence on grassland openness and structure. We predict that such measurements would provide a strong correlation with golf ball scores.

\section{Discussion}

The findings from these three datasets demonstrate the need for a nuanced approach when applying the golf ball method that is dependent on the productivity and disturbance history of a site. Hence, the method should continue to be employed across a range of grasslands, but the way the golf ball scores are interpreted will require careful consideration. We propose that because the method is a strong indicator of 'openness' in the Victorian Riverina. As the measure has been shown to be a good surrogate for Plains-wanderer population densities, this method can continue to be used by practitioners with confidence for this purpose. However, in other landscapes, particularly more productive landscapes such as the VVP, it is only through continued monitoring using more sensitive measures of cover within the ground stratum that we will be able to identify how golf ball scores relate to measures of grassland quality and habitat for fauna.

We advocate that other structural data, including cover of vegetation that is $<3 \mathrm{~cm}$ in height, be collected in conjunction with golf ball data - at least in the development stages of any management regime - to help highlight and understand the grassland attributes that the method is revealing. The method should not be used as an accurate surrogate for biomass or vegetation cover.

The examples we have illustrated demonstrate a demand for simple tools for monitoring grassland structure, such as the golf ball method. We believe the golf ball method is a useful technique, particularly as a measure of grassland openness. Nevertheless, we urge caution in how it is applied, and how the data it provides are interpreted. The method is particularly useful for testing for 
correlations between grassland structure (as represented by golf ball scores) and particular management targets, such as plant or animal diversity, or the presence and relative abundance of particular species. If such a correlation can be demonstrated, as is has been for the Plains-Wanderer, the method may provide a useful and cost-effective ongoing tool to help support management interventions. A further caution is to consider the rate of change of grassland states when using golf balls as a trigger for management interventions. Biomass can increase rapidly in wetter years, and grasslands can quickly change from an open to a closed grassland structure.

The golf ball method also provides a tool for community engagement and communication between land managers as it is rapid, easy and intuitive. The method provides a common language about grassland structure that can be adopted by practitioners of any level of ecological understanding. In this regard, it can assist the adaptive management of grassland ecosystems across Victoria.

247 Finally, the application of the golf ball method to a wide-range of grassland ecosystems provides a good example of a collaborative, cross-institutional approach to addressing important management issues. Stakeholders from different government agencies, not-for-profit organisations and research institutions have engaged in the method, and communicated openly about the results. This unified approach has allowed us to generate and share large datasets for testing the ability of the golf ball method to inform grassland management at a state-wide level, and demonstrated collaborative approach to addressing natural resource management issues.

\section{Acknowledgements}

Numerous agencies have provided support and funding for the development of the golf ball method: Parks Victoria, North Central Catchment Management Authority, the Australian Government, Trust for Nature, Department of Environment, Land, Water and Planning (DELWP), and the GlenelgHopkins Catchment Management Authority through funding from the Australian Government's National Landcare Programme via the Sustainable Environment, Threatened Species and Communities (SETSC) VVP Grassland Monitoring program.

References

Andreasen, C., Hansen, C. H., Møller, C. and Kjær-Pedersen, N. (2002) Regrowth of Weed Species after Cutting 1. Weed Technology 16, 873-879.

Antos, M. (2016) Northern Plains Grassland Fauna Surveys at Terrick Terrick National Park. July 2015-June 2016 progress report. Report to Parks Victoria, Melbourne

Baker-Gabb, D., Antos, M. and Brown, G. (2016) Recent decline of the critically endangered Plainswanderer (Pedionomus torquatus), and the application of a simple method for assessing its cause: major changes in grassland structure. Ecological Management \& Restorationn/a-n/a. 
Braby, M. and Dunford, M. (2006) Field observations on the ecology of the golden sun moth, 'Synemon plana' Walker (Lepidoptera: Castniidae). The Australian Entomologist 33, 103.

Brown, G. and Scroggie, M. (2012) Monitoring of the Threatened Hooded Scaly-foot Pygopus schraderi in North-central Victoria: Program Establishment and Initial Results. A Report to the Department of Sustainability and Environment, Parks Victoria and Trust for Nature., Arthur Rylah Institute for Environmental Research, Department of Sustainability and Environment, Heidelberg, Victoria.

Dorrough, J. and Ash, J. E. (1999) Using past and present habitat to predict the current distribution and abundance of a rare cryptic lizard, Delma impar (Pygopodidae). Australian Journal of Ecology 24, 614-624.

Gibbons, P., Briggs, S. V., Ayers, D., Seddon, J., Doyle, S., Cosier, P., McElhinny, C., Pelly, V. and Roberts, K. (2009) An operational method to assess impacts of land clearing on terrestrial biodiversity. Ecological Indicators 9, 26-40.

Griffith, C. and Nano, A. (2011) Moths in the Sun: Community monitoring for the Golden Sun Moth at Derrimut Grassland Reserve, Victoria 2008-2010. NatureWactch monitoring report No 1. Victorian National Parks Association, Melbourne.

Howland, B., Stojanovic, D., Gordon, I. J., Manning, A. D., Fletcher, D. and Lindenmayer, D. B. (2014) Eaten out of house and home: impacts of grazing on ground-dwelling reptiles in Australian grasslands and grassy woodlands. PloS one 9, e105966.

Howland, B. W., Stojanovic, D., Gordon, I. J., Fletcher, D., Snape, M., Stirnemann, I. A. and Lindenmayer, D. B. (2016) Habitat preference of the striped legless lizard: Implications of grazing by native herbivores and livestock for conservation of grassland biota. Austral Ecology 41, 461-470.

Lunt, I. D. and Morgan, J. W. (1999) Vegetation changes after 10 years of grazing exclusion and intermittent burning in a Themeda triandra (Poaceae) grassland reserve in south-eastern Australia. Australian Journal of Botany 47, 537-552.

Morgan, J. W. (1998) Importance of canopy gaps for recruitment of some forbs in Themeda triandradominated grasslands in south-eastern Australia. Australian Journal of Botany 46, 609-627.

Morgan, J. W. (2015) Biomass managment in native grasslands. Pages 201-222 in A. M. NSG Williams, JW Morgan, editor. Land of Sweeping Plains: Managing and Restoring the Native Grasslands of South-eastern Australia. CSIRO Publishing, Melbourne.

Morgan, J. W. and Lunt, I. D. (1999) Effects of time-since-fire on the tussock dynamics of a dominant grass (Themeda triandra) in a temperate Australian grassland. Biological Conservation 88, 379-386.

Noy-Meir, I. (1993) Compensating growth of grazed plants and its relevance to the use of rangelands. Ecological Applications 3, 32-34. 
Parks Victoria (2014) Parks Victoria Grassy Ecosystems Monitoring Protocol. Parks Victoria, Melbourne.

Richter, A., Osborne, W., Hnatiuk, S. and Rowell, A. (2013) Moths in fragments: insights into the biology and ecology of the Australian endangered golden sun moth Synemon plana (Lepidoptera: Castniidae) in natural temperate and exotic grassland remnants. Journal of insect conservation 17, 1093-1104.

Schultz, N. L. (2007) The effects of grazing exclusion on grassy ecosystems in Victoria, Australia. Honours thesis. La Trobe University, Bundoora, Australia.

Schultz, N. L. and Morgan, J. W. (2010) A Victorian grassland manager's guide to assessing vegetation state. A report to Parks Victoria, Melbourne.

Schultz, N. L., Morgan, J. W. and Lunt, I. D. (2011) Effects of grazing exclusion on plant species richness and phytomass accumulation vary across a regional productivity gradient. Journal of Vegetation Science 22, 130-142.

Seddon, J., Bathgate, A., Briggs, S. U. E., Davies, M., Doyle, S., Drielsma, M., Zerger, A., Gibbons, P. and Hacker, R. O. N. (2011) Comparing regional biodiversity benefits of investment strategies for land-use change. Geographical Research 49, 132-152.

White, A., Orr, D., Novelly, P. and Bastin, G. (2014) Tussock grasslands. In. Biodiversity and Environmental Change Monitoring, Challenges and Direction479-518.

\section{The golf ball method for rapid assessment of grassland structure}

\section{Figure captions}

Figure 1. Areas of plains grassland in Victoria. The two major areas are the plains grasslands of the Victorian Riverina (A) and the Victorian Volcanic Plain (B). Plains grasslands also occur in the Wimmera Plain $(\mathbf{C})$ and the Gippsland Plain (D). The grey shaded areas show the modelled 1750 distribution of the Plains Grassland ecological vegetation class. Data source: DELWP (2008) NV1750_EVCBCS https://www.data.vic.gov.au/data $\underline{\text { /dataset/native-vegetation-modelled-1750-ecological-vegetation-classes }}$

Figure 2. Two hypothetical grassland structures with equal biomass, but very different structure.

Figure 3. A scored photograph. The total visibility score is 15 . The golf balls in the blue circles have been scored as 1 , the golf balls in the green circles have been scored as 0.5 , and the golf balls in the pink circles have been scored as 0

Figure 4. Range of golf ball scores assigned by 21 independent observers, compared to benchmark golf ball score assigned by an expert. The diagonal black line represents a 1:1 relationship between observer and expert scores.

Figure 5. Correlations between golf ball scores vegetation attributes based on evaluations by La Trobe University in a range of grasslands across Victoria. Correlations with golf ball scores are presented for (a) 
340 vegetation cover $(\mathrm{n}=139, \mathrm{P}<0.001)$, (b) Aboveground biomass $(\mathrm{n}=139, \mathrm{P}<0.001)$, and (c) species richness $341 \quad(\mathrm{n}=139, \mathrm{P}=0.090)$.

342 Figure 6. Correlations between golf ball scores and vegetation attributes based on monitoring by Parks Victoria 343 in plains grasslands of the Victorian Riverina. Correlations with golf ball scores are presented for (a) vegetation 344 cover, (b) bare ground, (c) Grass cover $\times$ grass height, and (d) percentage of plot cover that is less than $12 \mathrm{~cm}$ in 345 height. All correlations are highly significant simple linear regression models (For each, $\mathrm{n}=2157, \mathrm{P}<0.001$ ).

346 Figure 7. Correlations between golf ball scores and vegetation attributes based on monitoring in Victorian

347 Volcanic Plains grasslands (ARI dataset). Correlations with golf ball scores are presented for (a) vegetation 348 cover on public land maintained by burning $(\mathrm{n}=120, \mathrm{P}<0.001)$, (b) vegetation cover on private land 349 maintained by grazing $(n=150, P=0.051$, (c) bare ground $(n=270, P=0.109)$, and $(d)$ grass cover $\times$ grass 350 height $(\mathrm{n}=270, \mathrm{P}<0.001)$.

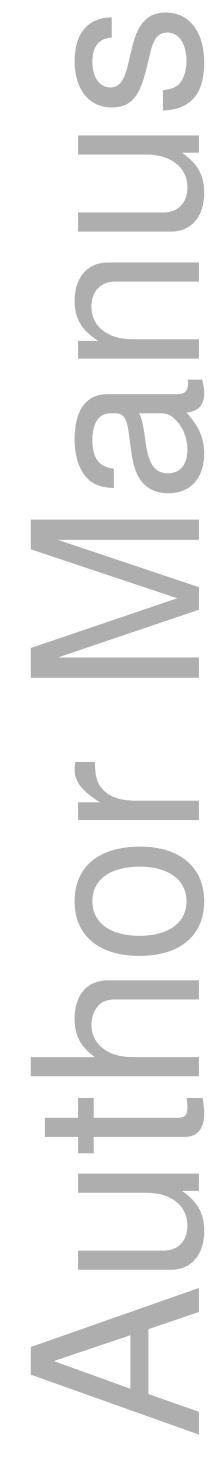



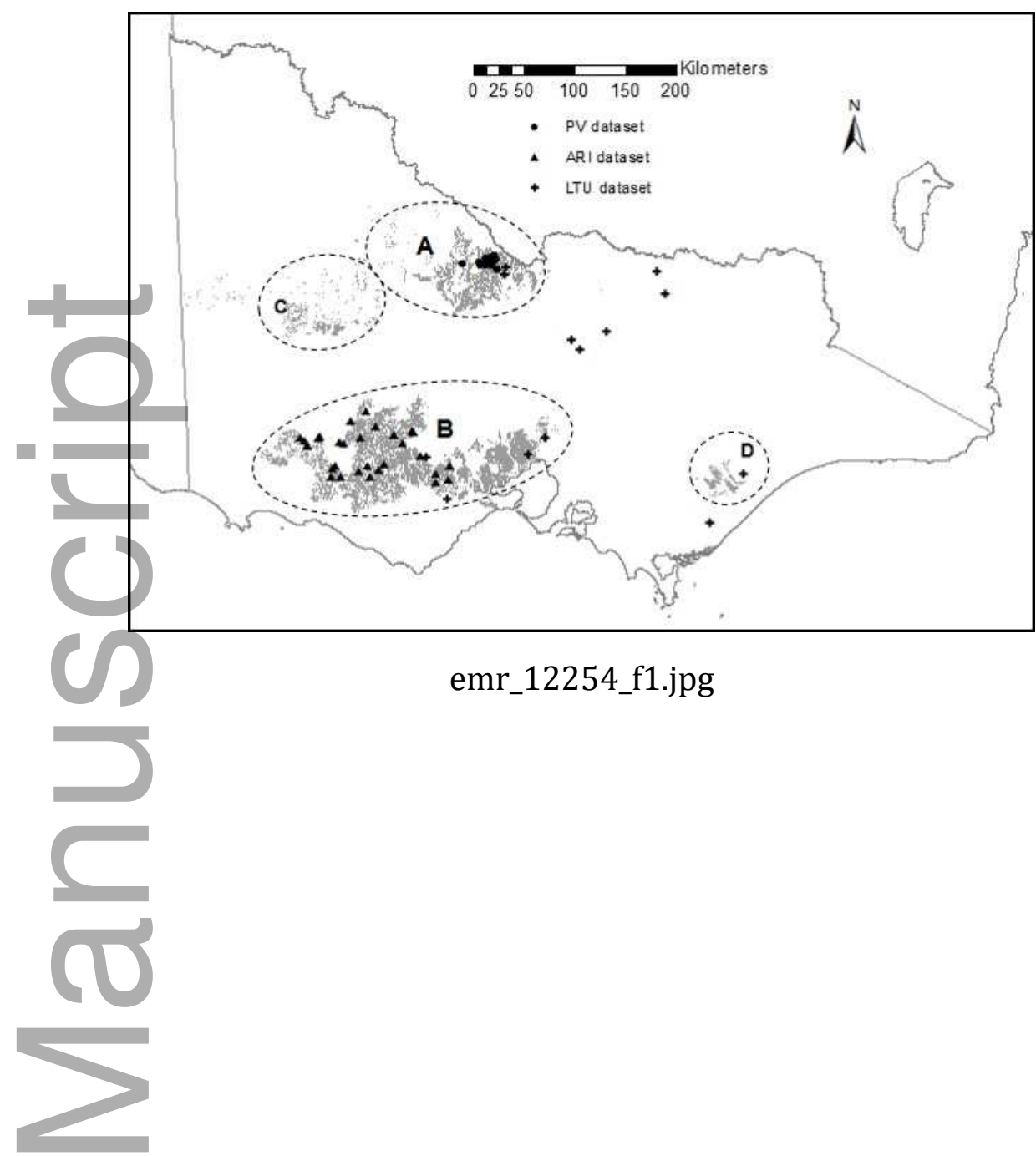

emr_12254_f1.jpg

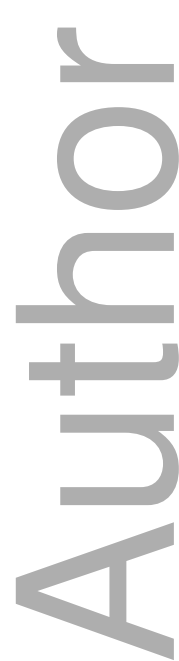

This article is protected by copyright. All rights reserved 

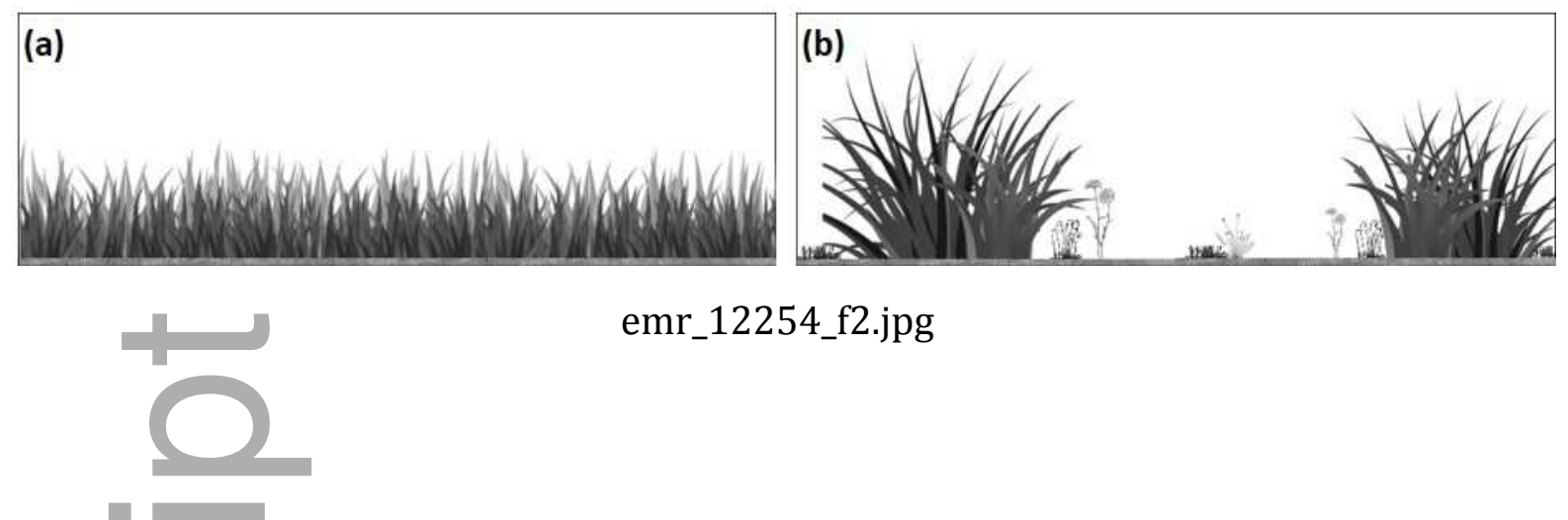

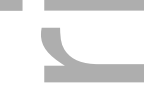
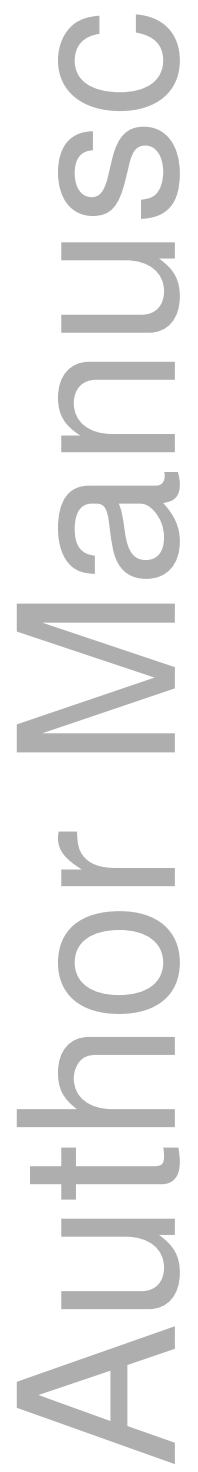

This article is protected by copyright. All rights reserved 

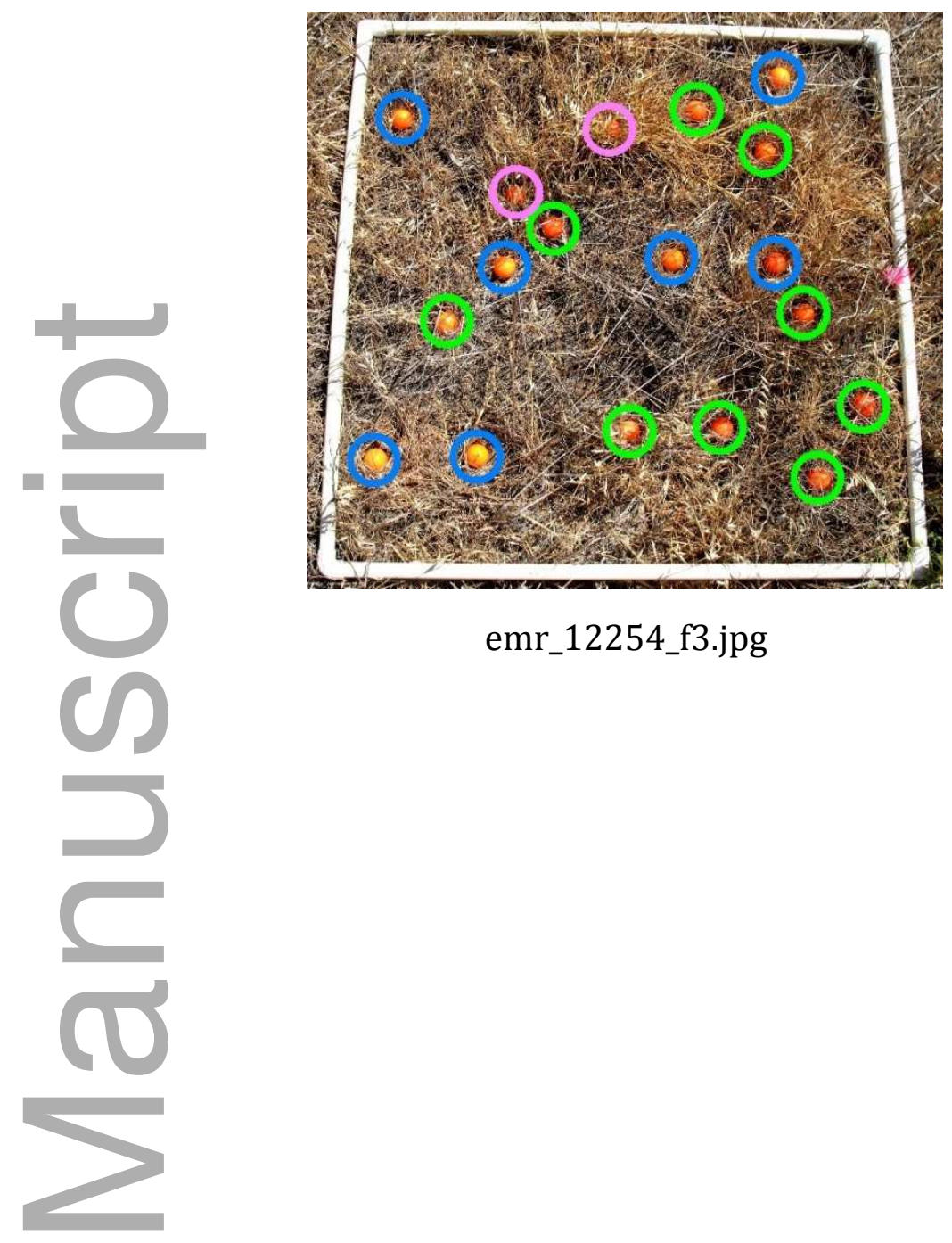

emr_12254_f3.jpg

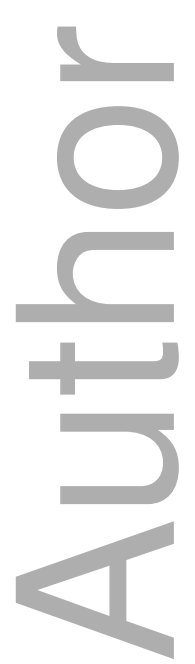




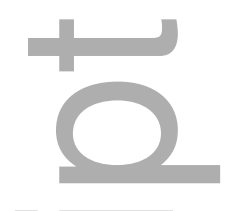

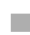
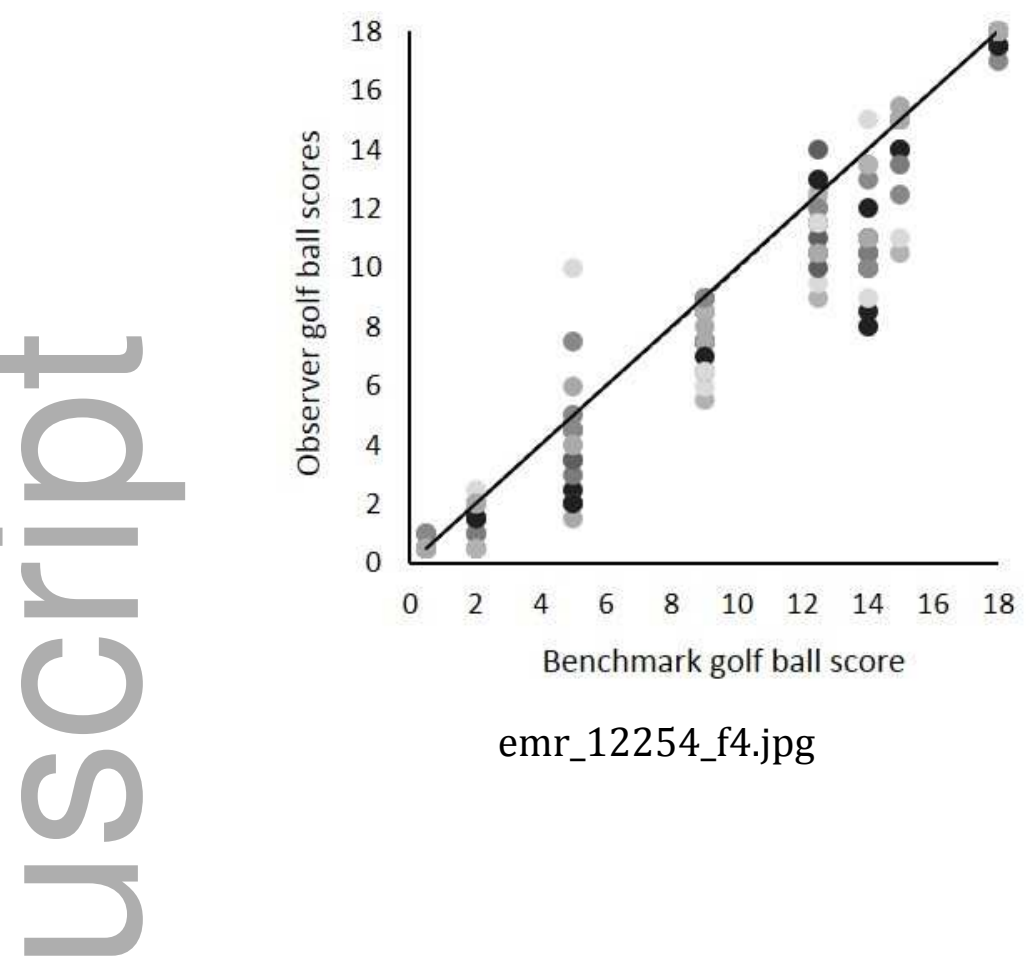

emr_12254_f4.jpg
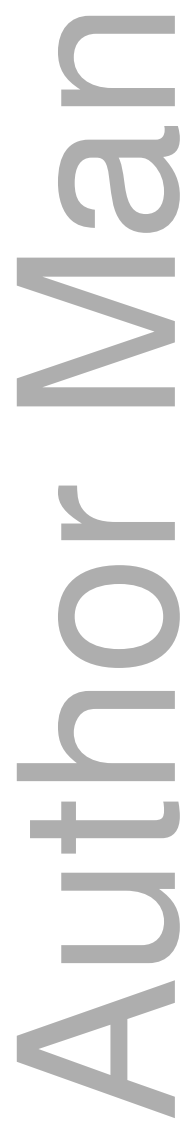

This article is protected by copyright. All rights reserved 

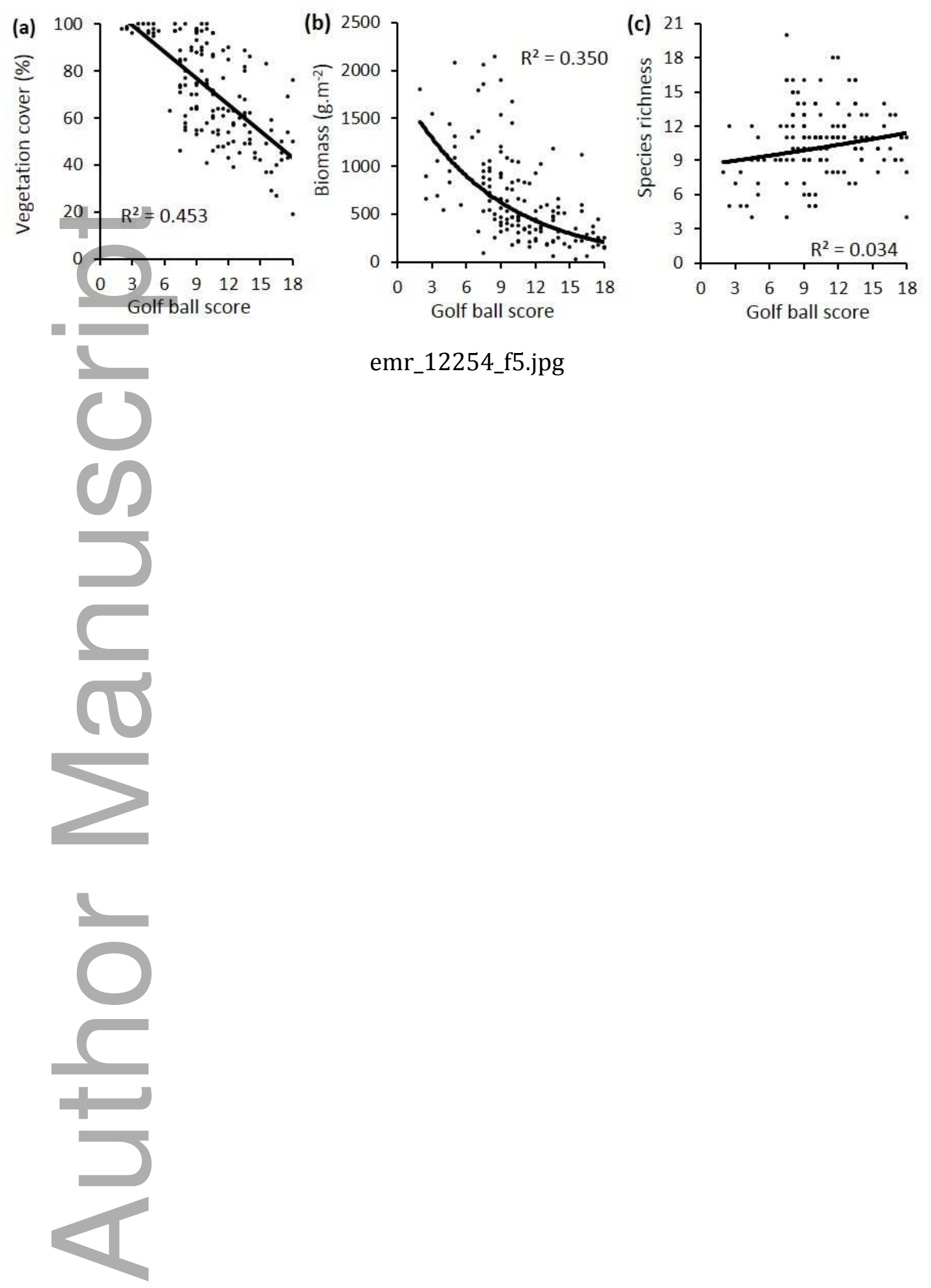

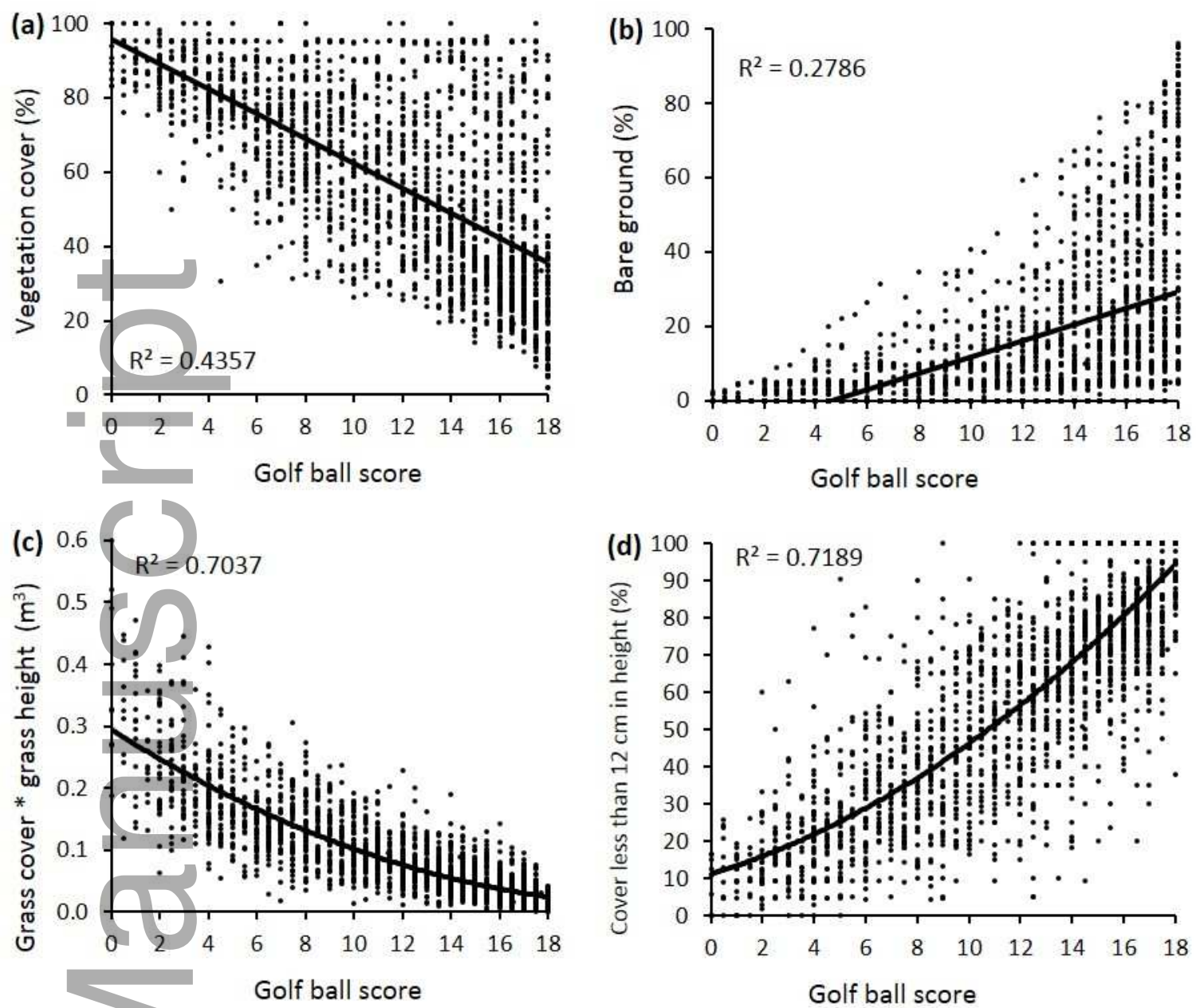

emr_12254_f6.jpg

This article is protected by copyright. All rights reserved 

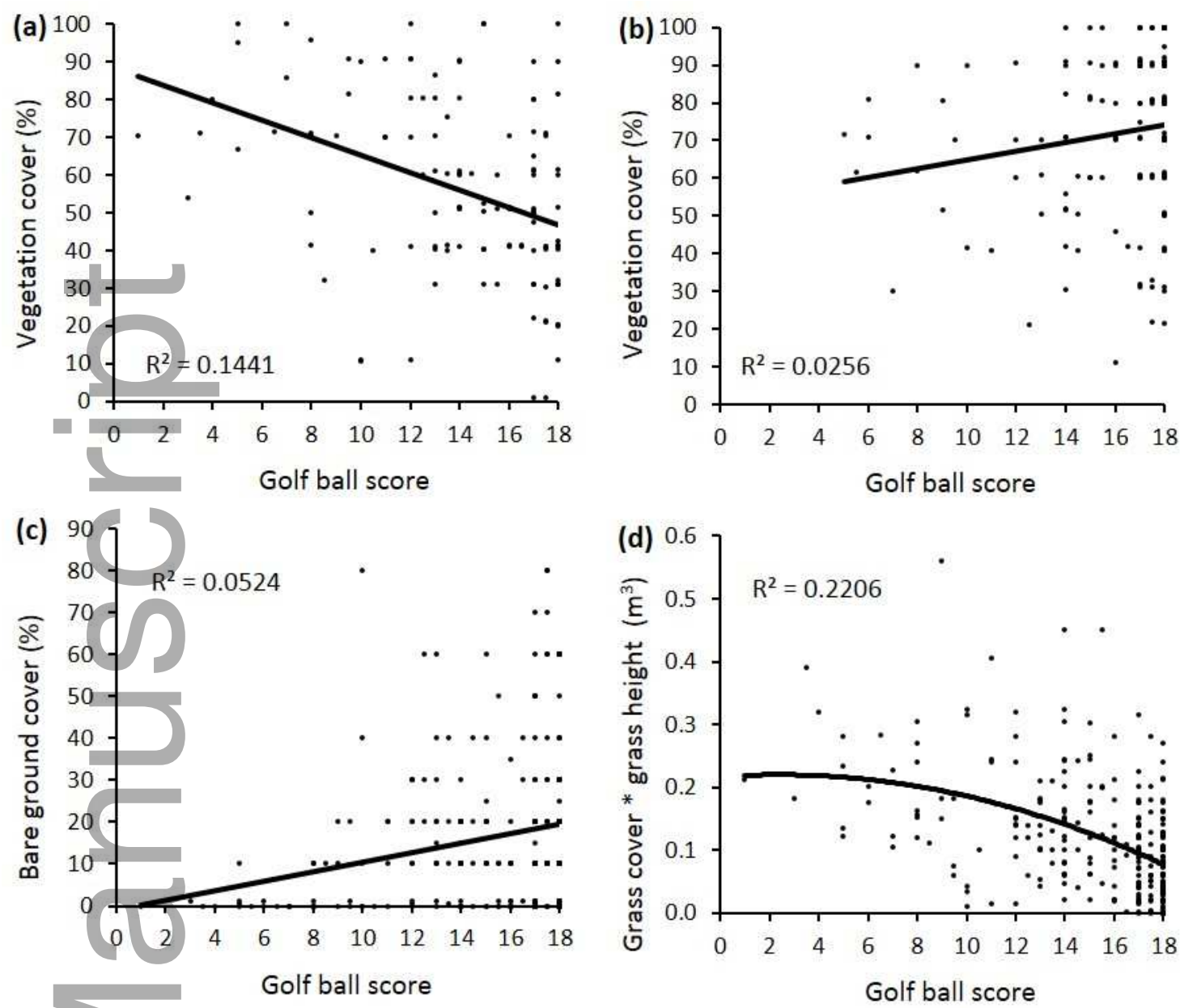

emr_12254_f7.jpg

This article is protected by copyright. All rights reserved 


\section{University Library}

\section{- M M N E R VA A gateway to Melbourne's research publications}

Minerva Access is the Institutional Repository of The University of Melbourne

Author/s:

Schultz, N;Keatley, M;Antos, M;Wong, N;Moxham, C;Farmilo, B;Morgan, JW

Title:

The golf ball method for rapid assessment of grassland structure

Date:

2017-05-01

Citation:

Schultz, N., Keatley, M., Antos, M., Wong, N., Moxham, C., Farmilo, B. \& Morgan, J. W. (2017). The golf ball method for rapid assessment of grassland structure. ECOLOGICAL MANAGEMENT \& RESTORATION, 18 (2), pp.134-140. https://doi.org/10.1111/emr.12254.

Persistent Link:

http://hdl.handle.net/11343/292758 